\title{
PRESENTACIÓN DE DOSSIER
}

M. Valeria Berros ${ }^{1}$

Este dossier temático de la Revista Papeles del Centro se integra con parte de los trabajos presentados en las «I Jornadas: Derechos y naturaleza. Debates en torno al problema ecológico», organizadas por el Proyecto de Investigación «Meulen. Renovación de aportes jurídicos sobre el problema ecológico» ejecutado durante el período 2017-2020 en el Centro de Investigaciones de la Facultad de Ciencias Jurídicas y Sociales de la Universidad Nacional del Litoral y la Secretaría de Investigación de la unidad académica mencionada.

Las Jornadas se llevaron a cabo el día 9 de marzo de 2021 en formato virtual debido a la pandemia Covid-19 sufrida a escala planetaria que, entre una pléyade de derivas heterogéneas, también ha renovado el interés y la preocupación por la cuestión ecológica y la multiplicidad de aristas que se asocian a ella.

Desde el proyecto de investigación que organizó este espacio académico se vienen desarrollando una serie de aportes desde el derecho en la construcción y revisión de estrategias existentes en torno al problema ecológico a partir de un enfoque socio-jurídico que considera especialmente el contexto local y latinoamericano, así como la relevancia social y actualidad del tema. Las dos líneas centrales de trabajo sobre las que se desplegaron los aportes del equipo que integran el proyecto

(1) Consejo Nacional de Investigaciones Científicas y Técnicas, Universidad Nacional del Litoral, Argentina. 
fueron la tutela legal de la naturaleza, la biodiversidad y los animales, por un lado, y la gestión de riesgos socio-ambientales y relativos a la salud humana, por el otro.

Si bien el abordaje de los temas se enfoca en el costado jurídico, se ha trabajado en diálogo permanente con otras disciplinas y saberes durante sus cuatro años de desarrollo. Es por ello que estas I Jornadas se propusieron como un ámbito de intercambio no sólo desde el campo del derecho sino también desde otras áreas y cuenta con vocación de permanencia. Esta vocación de constituirse como un espacio de intercambio permanente y periódico es un intento por generar un ámbito académico que, enfocado en la investigación socio-jurídica, sea robustecido por la diversidad de disciplinas y miradas posibles sobre las problemáticas ambientales contemporáneas.

Este dossier retoma los ejes a partir de los que se conformaron las mesas temáticas de las Jornadas y recupera el conjunto de ponencias que fueron especialmente reelaboradas por parte de sus autores y autoras y evaluadas a los fines de su publicación en este nuevo número de la revista Papeles del Centro.

En primer lugar, se presentan un conjunto de artículos que abordan el proceso de ampliación de derechos que implica el reconocimiento de derechos de la naturaleza desde facetas heterogéneas. En ese sentido, el trabajo titulado La transición entre el paradigma de la sustentabilidad y el reconocimiento de la naturaleza como sujeto de derechos de autoría de Cristian Fernández pivotea entre dos diferentes paradigmas que nutren este debate ambiental en la actualidad. A su vez, Bernardo Anibal Rossi Zibarelli se preocupa por este tema desde una perspectiva que lo lleva a articular derecho y literatura en el artículo titulado Naturaleza, Literatura y Derecho: El hombre que plantaba árboles de J. Giono y la sentencia de la Corte Suprema de Justicia de Colombia dictada con motivo de la deforestación de la Amazonía. Por último, también se encuentra presente la perspectiva del ecofeminismo para el abordaje de este tema en el trabajo de autoría colectiva de Laura Borsellino y Pablo Pereira Ecofeminismo y Derechos de la Naturaleza, cruces entre ley, Estado y sensibilidades.

En segundo término, dos artículos se enfocan en cuestiones relativas al derecho ambiental contemporáneo. Eduardo 
Olivero, con un enfoque general, se ocupa de analizar el contenido de la tutela del derecho a un ambiente sano desde una perspectiva crítica y propositiva bajo el título Los derecho «al» ambiente $y$ «de» naturaleza en acción emancipadora y ¿“contra-ponderativa»?. Por su parte, Matías Chaulet en la Tutela de los suelos en Argentina se dedica a un tema específico mediante una recuperación y análisis de las normas protectorias del suelo en nuestro país en diálogo con normativa procedente de diversas escalas regulatorias.

El tercer conjunto de contribuciones se enfoca en dos importantes ejes. El primero de ellos vinculado con el acceso a la justicia y el concepto mismo de justicia para pensar conflictos socio-ambientales. En esta línea aporta María Elicia Lobato con su texto Naturaleza, sociedad y conflictividad social: una mirada desde la justicia restaurativa y el equipo integrado por Marta S. Juliá, M. Cecilia Tello Roldán y M. Eugenia Villalba con la reflexiones contenidas en el artículo El acceso a la Justicia a través del Amparo ambiental a partir de la sanción de la Ley 10.208 en la provincia de Córdoba.

Las áreas naturales protegidas también son objeto de atención y ello se ve reflejado en el trabajo Bosques nativos, servicios ecosistémicos culturales y cambio climático: interrelaciones en el ámbito legal argentino-chileno de autoría de Clara María Minaverry, así como en el trabajo titulado Mecanismos legales para la protección ambiental de los bosques urbanos en cuatro municipios de la Provincia de Buenos Aires, Argentina realizado por Analía Scarselletta, Clara M. Minaverry, Macarena Pocaressi, Macarena López y Emiliano Cucciufo. A su vez, Norma Levrand aborda el tema en Científicos activistas, activismos epistémicos y gestión pública del ambiente en la gestión del Sitio RAMSAR Delta del Paraná 2016-2020. De esta manera, se cruzan perspectivas no sólo diversas en términos conceptuales sino también territoriales, aportando información desde la Patagonia, un sector de la Provincia de Buenos Aires y parte del Litoral.

Por último, se abordan problemáticas ambientales actuales. Se destaca aquí el trabajo de autoría colectiva de Camila González Limardo y Vanina Corral titulado El impacto del modelo extractivista en la cosmovisión indígena del territorio. 
Análisis conceptual y abordaje de casos en el que se entrelaza un análisis empírico con cuestiones conceptuales y aspectos jurídicos que permiten renovar preguntas sobre la necesidad de interrelación entre el derecho ambiental y el derecho indígena.

El conjunto de artículos que componen este dossier revisa una serie de problemáticas de especial actualidad y describe múltiples escenarios y desafíos. Aparecen interrogantes, perspectivas críticas y propuestas que renuevan y a la vez robustecen el debate sobre los posibles aportes que pueden construirse desde el campo jurídico. Apostamos a que esa construcción se realice mediante un diálogo con otros saberes y disciplinas que permita revisar la vinculación entre naturaleza, derecho y sociedad. 